\title{
How to Improve College Students' Oral English
}

\author{
Zhiyong Sun \\ Chifeng University 024000
}

\begin{abstract}
There are some problems in college English teaching, such as lacking of interaction between students and teachers, ignoring cultivating ability of communication, lacking of practice opportunities. Students are familiar with grammar, vocabulary and record materials, but the true ability is difficult to improve and develop. The final purpose of English teaching is cultivating students' communicative ability. This article, based on modern education theory, proposes methods of improving oral English ability through communicative teaching method.
\end{abstract}

\section{Key \\ words- \\ english, ability,education, communicative}

oral

\section{Introduction}

Nowadays, with the advent of globalization, English has playing a more and more vital role in different works, thus, college students also put the English studying in the first place. English is a subject with a series of abilities, such as listening, speaking, writing, which needs to lay emphasis on the practice. Oral English is one of the most important skills, it is also the weak link for the learners. However, during the process of studying English, many college students only care about how many vocabularies they have, how much grammar they have, how many articles they have read, and how many English news they have listened; oral English has always been ignored. Actually, the foundation meaning to learn a language is communication. It is necessary, useful and helpful to communicate with others in fluent English in your work and life. But, many English teachers are still in the misunderstanding that they prefer to teach students improve their listening and writing skills so as to pass the College
English Test, and there are so few opportunities for students and teachers to communicate in English. Therefore students' oral English go into a dead end.

\section{Problems and Solutions}

In China, we often call the English Studying as Deaf English. Because we take too much time and energy emphasize grammar. Although grammar will help reading and comprehension, we cannot make grammar as our main goal of teaching English. The main purpose of studying English is communication.

\section{A. Problems of Oral English teaching in} college.

1. Traditional teaching methods

The oral English teaching is still based on teachers-centered to vocabulary, grammaroriented line, oral English teaching class become listening teaching class, or it is only mainly keen on reciting sentences, which there are not enough opportunities for interaction of teachers and students. And students also don't know how to choose correct communication strategies and expressions to communicate with each others. What we do in most college English teaching class is still following the traditional teaching method which is just asking and answering. Students are totally in a passive role. Even the students have a good command of common expressions and customs, but there are still errors when they are really using them.

2. Class teaching is not consistent with the reality.

The traditional teaching methods make students keep the languages rules, independent sentences in mind, so students cannot command the language freely and flexibility. Students may not take speaker's identification, speaking occasions and appropriate language into account. 


\section{Lack of practice.}

Because of the above two problems, in the present English teaching, there are so little oral English practice opportunities. Students neither realize how important the language studying it is, and nor know how to put what they have learned into the true communications. Even some students thinks that they don't have any opportunities to practice oral English, so it is useless to learn it.

\section{B. Factors affecting oral English.}

\section{Factors of students themselves}

\subsection{Personal Emotion.}

In the English studying, personal emotions means that learner's attitude toward English and the using of English, opinions about relationships of mother tone and English. It includes interest, motivation, self-confidence, spirits of willpower and cooperation, which affected by integrated factors, like family, environment, studying methods and so on. Positive emotion can help students develop strong interest on English so as to inspire learning motivations. On the contrary, negative emotions stop studying.

\subsection{Thinking Habit of Mother Tongue.}

Chinese is our mother tongue. During the studying process, students prefer to use Chinese thinking habits and language habits to express English. They are familiar with those sentences which structures are very close. For example, "I like football","I have a computer". But when comes to "There are six people in my family", some students will say "My family have six people", and it is not the correct expression. Thus, thinking habits of mother tongue has become a serious obstacle for learning English.

2. Vocabulary

Vocabulary is an important part of language. Just as Wilkins, a British scholars, talked in College English Vocabulary Teaching, "People cannot express anything without vocabulary". Opinions and ideas cannot be expressed without large vocabulary, so it is necessary for college students to enlarge vocabulary. However, students will face many obstacles when they enlarge vocabulary, because they always forget the vocabulary they recited on yesterday night. Thus, many students, with a good command of grammar, because of lack of vocabulary, cannot talk to foreigners freely.

\section{Class Design}

Class size in most colleges of China are large, especially the bachelor's degree education. And in those classes, teachers and students just finish the teaching targets and the language receivers are classmates, their pragmatic failures cannot be corrected on time.

\section{Develop the teaching method and improve students' oral English.}

1. Improve students' oral English through communicative teaching method.

Modern oral English teaching lay emphasis on language function, start from daily communication and pay attention to what students say but not how to say. Teachers mainly keen on guiding students to start conversations and connecting them to students' needs, and improve oral English skills by language practice in and out of classes. That's the new teaching method what we are exploring.

When starting communicative teaching method, we should follow three principles: First, all activities should be concentrated on communication; then, communication process should be paid more attention as possible as we can; finally, teachers should not only pay attention to correct the mistakes that students made in the communication activities.

When taking communicative teaching method, teachers should not only follow three above principles, but also deal with relations between teacher and student, accurate and fluency, studying and thinking appropriate. Teachers must realize that as organizer and guide in communicative activities, teachers are not teaching them how to do it, but bringing them knowledge and encouraging students to study by themselves. The details of organizing include making a activity plan, giving a detailed instruction about each step, arranging tasks, assigning roles and letting students know about resources that they can use. 
2. Teachers should adopt various flexible forms of teaching.

In the oral English teaching class, in order to create a relaxed, natural and happier studying environment so as to fully mobilize students' enthusiasm and initiative of learning a language, teachers should adopt various flexible forms of teaching.

2.1 develop oral English skills through traditional teaching methods.

Because oral English skills are developed step by step, so we should adopt different teaching methods in different periods. At the beginning, activities mainly provide some input that can easily understand to improve listening comprehension. After that, expression is priority. Particularly the freshmen, who eager to express themselves, but at the same time they also afraid to say something or they cannot make it. So, teachers should take advantage of this opportunity to encourage students to talk in English and do more reading, listening and speaking practice to get rid of "silence period" of studying foreign language.

2.2 strength knowledge of background and culture

Because of the multi-culture, people in different backgrounds have different expression ways and habits. For example, daily greetings, such as apologize and appellation, various a lot in different backgrounds. The traditional teaching only cares about language form, and ignores language use, which cultivates "pure language ability". However, so many facts prove that "pure language ability" cannot guarantee that students can make an effective communication in a true situation. Successful English learning should be that students master social use of a language and can use it freely. That's to say, we should have a good command of capacity of social culture. Therefore, teachers should make detailed analysis when comes to cultural differences in the class so as to display the different culture and follow the provisional culture behaviors. If you truly eager to have a good command of a language, it is necessary for you to know more about its culture.
2.3 repeatedly practice formulistic expressions and sentence patterns.

Formulistic expressions take proportions in communication dialogues. Because using formulistic expressions not only accord with the economic principles in using language, but also, to some extent, increase the fluency of language. Loads of processing information in working memory can be lowed and working efficiency can be improved by using formulistic expressions. Students can not only improve the fluency of expression, but also, sometimes, can increase the accuracy by using formulistic expressions. So, using formulistic expressions is a strategy for studying foreign language as well as for communicating. After continuous practicing and reciting formulistic expressions and sentence patterns, students will be capability of using correct expressions in right occasions, and they even don't need to think about next sentence when talking with others.

2.4 Team discussion or debate can increase students' participation.

Discussion or Debate is that students express their own opinions on one topic. But they are different a lot. In the discussion, participators don't need to persuade the others, and they may come to a conclusion or not. In the debate, participators are divided into two teams and the two teams' opinions are totally contrary. One needs to persuade the others and proves its own accuracy and feasibility by any facts and anything. These kinds of activities can let students talk freely as well as bring more fun in the class. Students can be more relax and talk about whatever they want to talk.

2.5 practice in a truly occasion.

Language learners need a stage that they can study or act without any pressure. Language learners will be very nervous when they talk with others in a target language, and those nervous and afraid of making mistakes will affect they performance at a large scale. Thus, teachers should provide a relaxed stage and give more tolerance to mistakes students made in the activities, so as to keep students' enthusiasm and 
passion for English studying and activities' participation.

Because of the limitation of environment and conditions, class teaching is not easy to be very situational and true. So teachers must create some situation, the following are examples: (1) Picture Talk. Detailed situation can be displayed on the picture. At the beginning, teachers can use some simple and independent photos, then photos can be more difficult, like a comics. (2)Scenario assumes. Assume some situations, like making a call, seeing a doctor and going for a visit, which are familiar with every student, they have much to talk about. On the contrary, if teacher asks students to talk about supermarkets in the U.S.A, airports in England and Fashions of French and Italy, many students will keep silent. (3)Melodrama Performance. Melodrama Performance needs everyone to grasp his own role throw his emotions, understand the relationships of each role among the play and pay attention to development of plot of the play. It makes melodrama Performance to be one of the important teaching methods. Because students improve their ability of controlling emotions and expressing themselves when they in different occasions. In order to help students communicate with correct emotions, teachers must encourage students to grasp the role throw their true feelings, said lines and act with true emotions. When choose scripts, students should take script length, numbers of roles into account. Then, students need to study the scripts they have chosen or watch related videos so as to have a good command of all the script. Teachers also need to encourage students to make some outbreak about the characteristics of role based on their own understanding. Meanwhile, generally speaking, drama needs a long time rehearsal, which enrich students' leisure time.

For example, teachers can start activities around the topic of Smoking and Health. Firstly, some students act as smokers and journalist, let journalist ask smokers something about smoking; then, some students act as smokers and psychologist, and psychologist will analyze some deeper elements that make people be addicted in smoking; thirdly, students need to finish a play, which happens in a family, wife wants to stop husband smoking, but he doesn't listen to her and smoke heavily, and then they quarrel with each other.

\section{1ll. Conclusion}

With the increasing social development, the needs of talents are becoming larger and larger, especially those talents with high level of English, thus, improving college students' oral English has become an important task for college English teaching. Language is used for communication, but not for examination. Communicating with others fluency and effective is the true purpose of English teaching. English teaching is a systematic project, different methods should be adopted when facing different students and in different situations.

\section{References}

[1] Xuqiang. Communicative English Teaching and Assessment of Testing. Shanghai Foreign Language Education Press. 2000.

[2] Zhao Guoqiang. Discussion on English Teaching. Foreign Language Teaching. 2000,1 .

[3] Gu Xiaole, Huang Furong, Wangsong. Cooperative Learning and Melodrama Performance. Foreign Language Teaching. 2004,2 .

[4] Zhang Wenzhong. Studies On Oral Fluency of Second Language. 1999,2.

[5] Hu Chundong. English Teaching Method. Higher Education Press. 1999. 